\title{
Lógicas da antropotecnia: mensuração do homem e bio-sociologia (1860-1920)
}

Claude Blanckaert

Centre Alexandre Koyré - EHESS - CNRS

RESUMO

A antropometria é um método estatístico de análise do corpo humano criado por volta de 1850 para precisar o lugar do homem na natureza e definir os caracteres das raças humanas. Ela foi rapidamente utilizada para apreciar os fatores "biossociológicos" na origem da decadência ou da prosperidade das nações e discriminar os grupos sociais desviantes, criminais ou inadaptados. Os antropólogos esperavam manifestar assim sua competência especializada. Consideravam-se os únicos capazes de formular os verdadeiros fins da humanidade e os meios de apressar seus progressos. Esta ideologia profissional corrente foi criticada pelo anatomista Léonce Manouvrier, um adversário de Cesare Lombroso convertido à etiologia comum entre os sociólogos. Este artigo lembra os fundamentos da antropotecnia e os termos da controvérsia que opôs os teóricos da hereditariedade e do meio.

Palavras-chave: Antropometria; Biossociologia; raças.

\section{ABSTRACT}

As a statistical analysis of the human body, anthropometry was created in mid ninettenth-century in order to define the human place in nature and the physical features of races. It was rapidly applied to appreciate the "biosociological" factors governing the decadence or the prosperity of nations. It was used also to distinguish criminals or "degenarates". In doing so, the anthropologists wanted to push themselves forward as social experts. They persuaded themselves to be able to formulate the real goals of humanity and the means of its progress. This commom professional ideology was examined critically by the anatomist Léonce Manouvrier, who fighted with the Italian criminologist Cesare Lombroso and soon accepted the environmental etiology of the sociologists. This article examines the fundamentals of "anthropotecnie" and the development of heredity vs milieu controversy at the end of the nineteenth century.

Keywords: Anthropometry; Bio-sociology; races. 
Em 1919, o líder da escola americana de antropologia, Ales Hrdlicka, definiu sobriamente a antropometria como um "sistema de mensurações do corpo humano". Observou não ser esse sistema uniforme, dadas as variações do método segundo as finalidades pretendidas: a seleção militar não obedece ao mesmo padrão que a ergonomia, a identificação criminal ou os cânones estéticos. Além destes usos técnicos, Hrdlicka distinguiu um pólo de pesquisa pura chamado, não sem pleonasmo, "antropometria antropológica". Pretendeu assim atribuir-lhe um valor profissional e uma finalidade estritamente científica. Por tudo que diz respeito às partes do corpo sujeitas à mensuração - por peso, volumes ou extensão - a antropometria equivalia naquele momento à antropologia "física".

Hrdlicka detalhou o programa clássico dessa área desde 1918, na primeira edição do American Journal of Physical Anthropology, resumindo para seus leitores meio século de pesquisas biológicas. Tratava-se inicialmente de examinar o homem branco normal e a amplitude de suas variações orgânicas para servir de termo de comparação; em segundo lugar, de aprofundar o conhecimento dos primatas, campo de pesquisa que representa a antecâmara da história natural do homem; em terceiro lugar, de cons146 truir a filogenia humana segundo os recursos paleontológicos; em quarto lugar, de melhor apreender a diversidade das raças "mais primitivas", domínio segundo Hrdlicka, ainda abandonado ao arbítrio das pesquisas individuais. Este último ponto poderia bem, apesar de seu pesado preconceito não-igualitário, sobrepor-se aos anteriores: os Primitivos seriam de fato menos "mestiçados", menos "anormais", menos "patológicos" que as comunidades civilizadas. Sobretudo, eram reputados mais simples. Em seu estudo, pode-se portanto observar facilmente "o trabalho das leis naturais que controlam o ciclo da vida humana, suas adaptações e modificações”. Em uma palavra, o Primitivo apresenta-se como um laboratório da evoluçãa. ${ }^{2}$

Esse era o primeiro objetivo da antropometria: esclarecer o lugar biológico do homem na natureza e delimitar a particularidade de suas raças, não sem uma estereotipia. Por esta razão, pode-se afirmar que a antropometria nasceu na Europa e nos Estados Unidos da vontade de situar o homem entre as espécies vivas, e sobretudo de classificar os povos, de distribuí-los por grupos diferenciados, segundo princípios objetivistas e hierárquicos. De fato, os antropólogos não cessaram de distribuir raças e etnias, segundo sua categoria "natural" e méritos supostos, numa escala de excelência, os Brancos no ápice, os Negros ou os "selvagens" relegados 
ao universo dos macacos superiores. Esta leitura serial e genealógica, que se pensava confirmada pelas teorias evolucionistas, desenvolveu artes de mensuração inéditas nos meados do século XIX, notadamente em matéria craniológica e psicométrica.

De fato, a antropometria tomou impulso a partir de 1859 com a criação da Société d'Anthropologie de Paris por Paul Broca, professor da Faculté de Médecine de Paris. Alguns anos mais tarde, Broca era consagrado, na França e no exterior, como o fundador da antropologia moderna. Essa fundação apoiou-se em nada menos que a antropometria.

Entre 1860 e 1880, data da morte de Broca, surgiu aquilo que era chamado na literatura da época "manual operatório" da raciologia. Sem dúvida, Broca teve predecessores em antropologia física, desde Pierre Camper e Georges Cuvier até o médico escravista de Filadélfia, Samuel George Morton. Mas atribui-se a ele o crédito de ter reformado os métodos craniométricos com uma minúcia sem precedentes. ${ }^{3}$ Broca pretendia precisar os limites de variabilidade do gênero humano a fim de chegar a conseqüências fisiológicas sobre a aptidão - ou inaptidão - dos povos à civilização. Por sua capacidade de organizador da pesquisa, tornou profissional uma disciplina submetida durante muito tempo ao amadorismo. Vejamos as inovações.

Em primeiro lugar, a antropometria se opôs ao julgamento visual que dominava até então e que seria desacreditado como impressionista. Todos os caracteres físicos passaram a ser submetidos à mensuração e à classificação. Esta regra desdobrou-se numa outra recomendação que Broca impôs como um critério erudito: o emprego do método estatístico, o tratamento quantitativo dos dados que visa à maior objetividade e que obriga às investigações sobre séries ditas suficientes de crânios ou de medidas sobre o vivente. São portanto massas de homens que contam, não os indivíduos considerados exemplares. ${ }^{4}$

Em seguida, a generalização do uso de medidas implicou a concentração das coleções. Os museus não somente tinham uma função de exposição. Eles se confirmaram num papel experimental e didático, como se pode verificar com a criação do Laboratório de Antropologia da École Pratique des Hautes Études em 1868. Os seguidores de Broca encontraram ali acolhida e levaram mais longe seu ensinamento, notadamente Paul Topinard e Léonce Manouvrier, dos quais Hrdlicka foi aluno em 1896.

Enfim, a antropobiologia elaborou um léxico esotérico. Certos pontos de referência cranianos e osteológicos não pertencem ao registro da 
anatomia médica. Foram inventados por Broca por seu valor semiótico. $\mathrm{Na}$ mesma ordem de idéias, foi perseguida uma geometria das formas, toda uma panóplia de indícios, de ângulos mensurados sobre o vivente ou o esqueleto. O "manual operatório" exigia portanto instrumentos de outra natureza. Dezenas de cefalômetros, goniômetros, etc., suplantaram ou substituíram o compasso e a régua utilizados pela raciologia clássica. $\mathrm{O}$ recurso a essa aparelhagem, sua avaliação e sua unificação ocupam um lugar conseqüente nas discussões das sociedades antropológicas, dos congressos internacionais, etc.

Assim criada, a antropometria permitiu a profissionalização da pesquisa. De um lado, a determinação e a classificação das raças permaneceu o objetivo a ser alcançado, mas a sofisticação do procedimento anulou os recursos do autodidata. Os antropólogos deveriam aprender as regras técnicas e o manejo das instruções ${ }^{5}$. Esta codificação supõe o ensino. Portanto, ao fornecer à antropologia bases estáveis, Broca e seus sucessores procuraram reunir uma comunidade de especialistas perseguindo os mesmos objetivos. Os médicos seriam os mais numerosos a responder ao apelo. Definida como a biologia do gênero humano, a antropologia tendeu a restringir seu campo de ação apenas às considerações 148 anatômicas.

A que objetivos deveria servir esta ciência-diagnóstico? Nos anos 1860-1880, quando Broca e Topinard presidiam na França a organização dos estudos, pretendeu-se conhecer a diversidade do homem. Broca mantinha um ideal de um saber pretensamente neutro de toda implicação política. Esta divisão dos gêneros é duvidosa, sobretudo se considerados os preconceitos da época sobre a desigualdade das raças. Além disso, muitos antropólogos pensavam que a antropometria seria útil tanto às artes de governar como a uma colonização "científica”, desconsiderando assim a diferença entre a pesquisa pura e sua aplicação.

Desde seu nascimento, a antropometria procedeu de outras exigências, quase obsessionais, relativas à vitalidade geral das populações. Daí vem o interesse pela demografia, pelas condições sanitárias das cidades e dos campos, das fusões étnicas que configuraram velhas nações e dos riscos de decadência biológica que arruinaria sua marcha progressiva em direção à civilização. Na esteira de Gobineau e de B. A. Morel, a ameaça da degenerescência mobilizou os antropólogos que se inquietaram com fatores hereditários explicando o aumento do crime ou as dificuldades da adaptação em ambiente industrial ${ }^{6}$. Como explicou Georges Papillault, professor da École d'anthropologie de Paris, o "valor de uma sociedade, 
de um dado meio cultural [sic] explica-se, em grande parte, pelo valor dos indivíduos que a compõem". ${ }^{7}$ Em outras palavras, é o que diz também Henri Thulié, diretor da École:

Se é útil para a satisfação do homem saber de onde vem e quais foram seus erros, é mais útil ainda apoiar-se sobre esses conhecimentos para esforçarse em saber para onde vai; é a antropologia que pode indicar-lhe isto. Assim como o estudo do homem em sua anatomia e na fisiologia traz noções para sua higiene e para o tratamento de suas doenças, também o estudo dos povos nas raças que os compõem, em suas necessidades sociais, em sua perfectibilidade, em suas grandezas como em suas fraquezas, pode indicar em que sentido o destino dessa nação deve evoluir. ${ }^{8}$

Assim, todo um modo de controle social cientificamente construído voltou-se para o espaço interior. A biopolítica das raças brancas se define mais precisamente no contexto dos patriotismos. Esta auto-racização, este enraizamento das nacionalidades representam uma parte não desprezível do programa antropométrico. Após haver desenhado o quadro da pesquisa em antropologia geral, Hrdlicka lembra, por exemplo, a urgência e a importância desses procedimentos práticos. Enumera alguns temas clássicos que se encontram na literatura européia contemporânea, e nos mesmos termos: os efeitos da mestiçagem entre raças diferentes, a limitação da imigração de estrangeiros de variada extração, a parte do inato e do adquirido nas gerações, os problemas de aclimatação nas colônias, a detecção das frações "degeneradas" da humanidade (alcoólicos, epilépticos, loucos, pervertidos e criminosos). ${ }^{\text {? }}$

Para Hrdlicka, a eugenia seria uma antropologia aplicada. O saber acumulado poderia indicar as tendências evolutivas atuais e futuras. A antropologia abre-se então para a prospectiva. Ela possuiria vocação de orientar as escolhas políticas no que diz respeito à legislação, à regulação das populações e sua saúde. $\mathrm{O}$ autor recorre a ela em estudos sobre os princípios diretivos da hereditariedade humana. Insiste sobre a necessidade de formular "as verdadeiras metas da humanidade, físicas e intelectuais”, a fim de trabalhar para sua realização. Para tanto, Hrdlicka, como seus colegas da Europa, preconizavam a implantação de um controle antropométrico nacional, em caráter permanente, em cada país civilizado. Os dados recolhidos serviriam de índice do "progresso, da estagnação ou da deteriorização" das sociedades e seriam de importância vital para as decisões de caráter eugênico e jurídico.

O desenvolvimento da antropologia dependeu pois, igualmente, tan- 
to de um programa disciplinar próprio da raciologia quanto de pretensões intervencionistas que se tornaram mais prementes no final do século XIX. Os antropólogos deveriam cerrar fileiras e falar em uníssono. Após a Grande Guerra foi criado em Paris o Institut international d'Anthropologie, cujo alcance prático privilegiava a pesquisa desinteressada, declarada rotineira: "as sociedades humanas esperam de vossos esforços as diretivas mais indispensáveis à sua fecundidade, à sua reprodução aperfeiçoada e à sua prosperidade”. ${ }^{10}$

A esses saberes, distintos por sua aplicação de uma simples monografia do gênero humano, era preciso dar um nome, um estatuto teórico, até mesmo contornos legítimos. Em 1889, por ocasião da reunião parisiense da Association française pour l'Avancement des Sciences (AFAS), Léonce Manouvrier propôs denominar antropotecnia o conjunto das "artes que têm por objetivo a direção da humanidade", isto é, a medicina, a higiene, a moral, o direito, a política e a educação ${ }^{11}$. Ora, nem a data, nem a palavra nem a personalidade de seu inventor são indiferentes. Professor de antropologia fisiológica na École d'Anthropologie de Paris desde 1887, Léonce Manouvrier era a estrela ascendente da ciência do homem. Último discípulo de Broca, titular em 1881 de uma tese de medicina sobre a anatomia cerebral em suas relações com o crânio, ele ministrava seu ensino antropométrico no laboratório da EPHE do qual era o preparador titular desde 1880 . Sua reputação era tanta, observou posteriormente Raoul Anthony, "que nenhum antropologista no mundo poderia hoje deixar de se considerar como seu aluno, direta ou indiretamente”. ${ }^{12}$ É o caso, especialmente, de Hrdlicka, que segundo seu amigo Henri Vallois, era "inteiramente ao estilo da antropologia francesa". ${ }^{13}$ A influência de Manouvrier era portanto incontestável. Ele acede ao secretariado-geral da Société d'Anthropologie de Paris em 1902, à direção do laboratório dos Hautes Études em 1903, nos anos em que os incidentes práticos da genética mendeliana, do selecionismo neodarwinista ou do organicismo social pareciam dar uma nova carreira às ambições hegemônicas do mundo médico.

A palavra antropotecnia, em sua extensão ampla, cobre o registro do conjunto de técnicas de gestão do corpo social. Por analogia com a zootecnia, a arte dos criadores destinados ao melhoramento das raças de animais domésticos, ela sugere formas abruptas de eugenismo ou de reducionismo biológico. De fato, Manouvrier afirmou em 1889 sobre a moral :

Nada mais é que um complemento elevado da Higiene: é a arte de dirigir a humanidade em direção ao progresso e à felicidade, a arte de regular nesse 
sentido a conduta dos Homens. O Direito, tomado em sua acepção mais ampla, é a arte de regulamentar e de sancionar os preceitos de Higiene e de Moral suscetíveis de se tornarem obrigatórios no interesse das sociedades. A Educação é a arte de endireitar os homens de acordo com os preceitos das artes precedentes. ${ }^{14}$

Manouvrier nunca se ocupou da pesquisa científica em sua finalidade específica sem levar em conta, como indicou em 1907, as "preocupa-

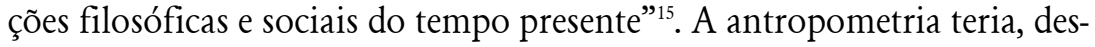
se ponto de vista, um alcance reformista por suas aderências aos interesses mais imediatos da humanidade.

Como observou Manouvrier em 1889, o aparecimento recente da antropologia criminal assinalaria a chegada de um "novo estado de coisas". De fato, foi tendo em vista uma comparação com a escola lombrosiana que Manouvrier interrogava desde 1883 a biologia dos criminosos e esforçava-se por completar seu exame diagnóstico ${ }^{16}$. A estatística lhe revelava, por exemplo, um certo facies "brutal", do qual os estigmas cranianos dos criminosos ( pequenez da testa, mandíbula forte, etc.) indicavam o diferencial de evolução, a fraquíssima intelectualidade. Os delinqüentes não seriam alienados ou monstros mas "retardados". Nos anos do triunfo de Cesare Lombroso, que correspondem muito proximamente ao primeiro Congresso de Antropologia criminal de Roma de 1885, Manouvrier não hesitou em estabelecer correlações entre a morfologia de conjunto e os traços de comportamento morais assimilados aos instintos retrógrados. Ele não falava de criminoso nato, mas seus estudos concluem na mesma direção: o livre arbítrio, suposto nos tribunais, seria uma quimera metafísica. A antropometria teria, portanto, com este exemplo, um valor sinalizador e sobretudo prognóstico destacado em muitas páginas. O monopólio de competência da antropologia foi lembrado por Manouvrier em 1889. É claro que a exigência antropotécnica poderia prevalecer-se de uma experiência recente. Mas os "engenheiros" de um novo gênero que ele procurava deveriam receber uma educação científica sem a qual sua arte seria cega. ${ }^{17}$

Apesar dessas fórmulas, e sem renegar o conceito de antropotecnia ao qual ele assegurarou larga difusão, o elo entre a ciência do homem e suas aplicações sociais procede em Manouvrier de outras escolhas técnicas e de uma crítica radical da objetividade antropométrica. Foi também em 1889, data comemorativa da Revolução, que a opinião anterior de Manouvrier voltou-se para a apostasia. Em agosto ocorreu em Paris o julgamento internacional da antropologia criminal. Sem explicar sua mu- 
dança de posição, Manouvrier se declarou convencido da etiologia social dos atos delituosos. Segundo ele, Lombroso estava errado ao pretender ligar o crime, juridicamente definido, às condições anatômicas "de um modo tão estreito que se tornava quase uma função, um simples resultado fisiológico ao qual o meio exterior não contribuiria senão a título de causa ocasional' ${ }^{p 18}$. Nestas matérias complexas, o elemento físico não constituiria nem uma justificação, nem um destino. Contradizendo seus primeiros trabalhos, Manouvrier afirmava agora que o atraso orgânico não equivaleria a estados mentais. Portanto, seria errôneo estabelecer, como a antiga frenologia, uma relação direta entre o elemento anatômico e tendências homicidas. Fazê-lo equivaleria a esquecer que o primeiro não "determina" os segundos em condições apropriadas de educação, sem uma trajetória individual ou familial que explique, melhor que todo outro determinante biológico, a passagem ao ato. Em suma, o criminoso não seria uma variedade humana distinta da qual pudesse ser traçado o retratotipo segundo a doutrina do criminoso atávico, ele seria " sobretudo um produto sociológico".

Aderindo a Lamarck, Manouvrier justificou desde então pela influência das circunstâncias do meio social todas as condutas que se acreditava congênitas ${ }^{19}$. Ele permaneceu senão o mais conhecido, o mais constante dos teóricos da "Escola dos meios" que ambicionou transformar o homem mudando seu quadro de existência. No fundo, Manouvrier não era menos fatalista que Lombroso, mas, segundo sua metáfora, o homem seria um produto do meio. Um outro ambiente social produz uma outra divisão. O homem poderia chegar à autodeterminação quando controla, isto é, compreende na medida do possível, os mecanismos desencadeadores de seus comportamentos pessoais ou coletivos. Num clima hostil, o homem honesto pode vestir-se de assassino. Só lhe falta a ocasião. E do mesmo modo o criminoso em potencial pode ser redimido se arrancado do círculo das influências "desencaminhadoras"! A tese da predestinação, dos vícios e talentos inatos passou a ser rapidamente considerada por Manouvrier condenável em seus excessos e inútil em suas aplicações. Efetivamente, a antropotecnia é também definida como "o conjunto de artes que tem por meta a ação do homem sobre si mesmo e sobre seus semelhantes"20, proposição atribuída às escolhas mesológicas doravante estampadas pelo professor: "entre o crime e os caracteres anatômicos existe todo um mundo, o meio exterior". ${ }^{21}$

O "duelo com Lombroso" de 1889 serviu de catalizador para os mais audaciosos avanços. Nos anos seguintes, Manouvrier combateu toda a 
herança racista, sexista e reducionista da antropometria vinda de Paul Broca. Pretendia denunciar os usos estéreis e perigosos da antropologia, dos quais a "pseudo-sociologia” racista e anti-semita de Georges Vacher de Lapouge, Gustave Le Bon e Jules Soury lhe pareciam a caricatura "ultra"22. Mas ele pretendia ao mesmo tempo justificar a importância social da ciência do homem, como sua posição destacada na Société e na École d'Anthropologie exigia. A precariedade desta posição não ocorre portanto sem motivos. ${ }^{23}$

A antropotecnia defendida por Manouvrier se posicionou contra a ditadura das cifras, contra a concepção das aptidões inatas e da desigualdade das raças humanas, em favor da reabilitação do papel das mulheres na cidade. Trata-se de um paradoxo de um professor de antropologia fisiológica, demonstrador da anatomia do homem no laboratório da EPHE e grande mensurador de crânios, que trabalhava subterraneamente pela emancipação da ciência social e que será, por essa razão, apreciado pelos durkheimianos $^{24}$. De fato, Manouvrier levou em sua comunidade um combate quase solitário. Sem bater-se de frente com seus colegas racistas da École d'Anthropologie, ele se voltou para o monogenismo, refutou as teses hereditaristas de Georges Hervé ou de Georges Papillault e, longe de dar razão aos temores do fim-de-século relativos à nocividade dos cruzamentos raciais, concluiu pela "identidade fundamental da inteligência dos Negros e da nossa". 25

As posições sociologistas de Manouvrier se confirmaram no decorrer do primeiro quartel do século XX. Elas foram, na verdade, colocadas desde 1889. Em sua conferência da AFAS, longe de promover uma extensão do campo de aplicação da antropometria, ele a colocou em limites estritos:

Cabe aos moralistas, juristas, educadores e políticos serem os reformadores de suas artes respectivas, como os médicos reformaram a arte medical. Eles contribuirão dessa forma para os progressos da Antropologia sociológica e psicológica, como os médicos contribuíram para os progressos da Antropologia anatômica, fisiológica, patológica ${ }^{26}$.

Segundo Manouvrier, a antropotecnia equivaleria portanto a uma "sociotecnia" cientificamente esclarecida, uma engenharia social. Este segundo conceito será preferido por Paul Topinard ${ }^{27}$. O primeiro foi preferido por Manouvrier por razões epistemológicas: convencido de que a ordem dos fenômenos sociais seria comum ao homem e ao animal, Manouvrier quiz individualizar pelo radical anthropos todos os conhecimen- 
tos relativos à humanidade. Aplicadas aos seres vivos em geral, as verdades biológicas ou sociológicas permanecem atípicas. Elas se circunstanciam todavia quando se trata de analisar os fatos aferentes a esta ou aquela espécie. Isso ocorre tanto na sociologia como na biologia humana. Uma monografia completa do homem deve ser necessariamente anatômica, fisiopsicológica e sociológica, e Manouvrier indica que cada ordem de fenômenos é regida por leis especiais. Desse modo, a sociologia dos agrupamentos humanos não é redutível de maneira alguma à estatística de cubagens cranianas e, do mesmo modo, a psicologia individual não pode ser deduzida de um cânone antropométrico. O conjunto, essa combinação em níveis, define a antropologia geral.

Todas essas nuances, onde se encontra o interesse de Manouvrier pela filosofia de Auguste Comte, foram muito negligenciadas pelos seus contemporâneos. Georges Papillault, seu aluno e sucessor no laboratório, optou, como Hrdlicka, pela detecção dos degenerados, pela higiene racial e pela biossociologia dos "instintos" nacionais. Manouvrier pretendeu mudar a sociedade e reformar seus abusos, Papillault ambicionava curar as " moléstias sociais"28. Curiosamente, a palavra antropotecnia retornou após a Segunda Guerra Mundial nos textos de Jean Schunck de Goldfiem com conotações morfopsicológicas e eugenistas formalmente ausentes dos textos de Manouvrier. Nesta refundação seria preciso assinalar outras tradições heurísticas. Schunck de Goldfiem, na verdade, rendia homenagem ao "nosso venerado mestre G.Papillault"

\section{NOTAS}

${ }^{1}$ HRDLICKA, A. Anthropometry. American Journal of Physical Anthropology, 2, n. 1, 1919, pp. 43-46. Tradução deste artigo por Teresa Malatian.

${ }^{2}$ Idem. Physical anthropology: Its scope and aims. American Journal of Physical Anthropology, 1, n.1, 1918, pp. 18-20.

${ }^{3} I d e m$, p. 6.

${ }^{4}$ BLANCKAERT, C. "Méthode des moyennes et notion de 'série suffisante' en anthropologie physique” (1830-1880). In: FELDMAN, J, LAGNEAU, G e MATALON, B (org.). moyenne, milieu, centre. Histoires et usages. Paris: Ed. de l'EHESS, 1991, pp. 213-243.

${ }^{5}$ Id., "Le 'manuel opératoire' de la raciologie. Les instructions aux voyageurs de la Société d’Anthropologie de Paris” (1860-1885). In: Le Terrain des Sciences humaines. Instructions et Enquêtes (XVIIIe - Xxe s.). Paris: L’Harmattan, 1996, pp. 139-173.

${ }^{6}$ Ver a síntese de D.Pick, Faces of Degeneration. A European Disorder, c.1848-1918. Cambridge: Cambridge University Press, 1989. 
${ }^{7}$ PAPILLAULT, G. La bio-sociologie. Son but, ses méthodes, son domaine, ses applications. Revue anthropologique, 22, 1912, p. 17.

${ }^{8}$ THULIÉ, H. “L’ École d'Anthropologie depuis sa fondation”. In: 1876-1906. L'École d'Anthropologie de Paris. Parais: Félix Alcan, 1907, p. 24.

${ }^{9}$ HRDLICKA, A. Physical anthropology. Op. cit, pp. 20-23.

${ }^{10}$ CAPITAN, L. Rapport général [réunion préparatoire pour la fondation de l'institut international d'Anthropologie]. Revue anthropologique, 30, 1920, p. 216.

${ }^{11}$ MANOUVRIER, L. "Classification naturelle des sciences. Position et programme de l'anthropologie”. In: Association française pour l'Avancement des Sciences. Compte rendu de la $18^{e}$ session. Paris, 1889. Seconde Partie. Notes et mémoires. Paris, 1890, p. 678.

${ }^{12}$ ANTHONY, R. Léonce Manouvrier. Revue anthropologique, 37, 1927, p. 159.

${ }^{13}$ BOCQUET-APPEL, J.-P. Interview de Henri-Victor Vallois [15.2.81]. Bulletins et Mémoires de la Société d'Anthropologie de Paris n.elle série, 8, n. 1-2, 1996, p. 89.

${ }^{14}$ MANOUVRIER, L. op. cit., p. 679.

${ }^{15}$ Id., “Anthropologie physiologique”. In: 1876-1906. L'École d'Anthropologie de Paris, cit., p. 45.

${ }^{16}$ BLANCKAERT, C. "Des sauvages en pays civilisé. L'anthropologie des criminels (18501900). In: MUCCHIELLI, L. (dir.). Histoire de la criminologie française. Paris: L’Harmattan, 1994, 70 ss.

${ }^{17}$ MANOUVRIER, L. Classification naturelle... op. cit., pp. 680-681.

${ }^{18}$ Id. "Discussion”. In: Actes du deuxième Congrès international d'anthropologie criminelle (Paris, août 1889). Lyon: A. Storck, 1890, p. 156.

${ }^{19}$ BLANCKAERT,C. "L'anthropologie lamarckienne à la fin du XIXe siècle. Matérialisme scientifique et mésologie sociale”. In: LAURENT, G. (dir.). Jean-Baptiste Lamarck 1744-1829. Paris: CTHS, 1997, p. 625 ss.

${ }^{20}$ MANOUVRIER, L. "De l'anthropologie criminelle considerée comme une branche de l'anthropologie juridique - A place dans l'anthropologie". In: Actes du deuxième Congrès international d'anthropologie criminelle, cit., p. 177.

${ }^{21}$ Id., “Discussion”. In: Actes... op. cit., p. 276 ss, cit., p. 284.

${ }^{22}$ Id., L'indice céphalique et la pseudo-sociologie. Revue de l'École d'Anthropologie, 9, 1899, pp. 233-259. A propósito deste contexto político-intelectual, vide TAGUIEFF, P.-A. La couleur et le sang. Doctrines racistes à la française. Ed. Mille et une nuits, 1998.

${ }^{23}$ HECHT, J.M. A vigilant anthropology: Léonce Manouvrier and the disappearing numbers. Journal of the History of the Behavioral Science,33, n. 3, 1997, pp. 221-240.

${ }^{24}$ MUCCHIELLI, L. La découverte du social. Naissance de la sociologie en France (1870-1914). Paris: La Découverte, 1998, pp. 286-289.

${ }^{25}$ MANOUVRIER, L. "Discussion”. In: Annales de l'Institut international de Sociologie, 2, 1896, p. 380. Sobre a questão dos cruzamentos e o valor dos mestiços, ver F.M. ZERILLI. Il dibattito sul meticciato. Biologo e sociale nell'antropologia francese del primo novecento. Archivio per l'antropologia e la etnologia, 125, 1995, p. 237-273. 
${ }^{26}$ MANOUVRIER, L. "Classification naturelle des sciences..., cit., p. 681.

${ }^{27}$ TOPINARD, P. Science et foi. L'anthropologie et la science sociale. Paris: Masson et Cie., 1900, p. 374.

28 "Le crime, la prostitution, la dégénérescence, la stérilité des classes les plus instruites et des peuples les plus civilisés, etc.” G. PAPILLAULT, La bio-sociologie, op. cit., p. 18. Comparar, para a mesma data, a pesquisa de Manouvrier publicada na mesma revista, Quelques cas de ciriminalité juvénile et commençante. Revue anthropologique, 22, 1912, pp. 297315 e $420-438$.

${ }^{29}$ GOLDFIEN, J. Schunck de. Anthropotecnie. Paris: Calman-Lévy, 1948, pp. 12-13. O autor se apresenta como " diretor do Institut d'anthropotecnie". 